\title{
Current Status of Thyroid Fine-Needle Aspiration Practice in Thailand
}

\author{
Somboon Keelawat \\ Samreung Rangdaeng ${ }^{1}$ \\ Supinda Koonmee ${ }^{2}$ \\ Tikamporn Jitpasutham \\ Andrey Bychkov
}

Department of Pathology, Faculty of Medicine, Chulalongkorn University, Bangkok; ${ }^{1}$ Department of Pathology, Faculty of Medicine, Chiang Mai University, Chiang Mai; ${ }^{2}$ Department of Pathology, Faculty of Medicine, Khon Kaen University, Khon Kaen, Thailand

Received: August 3, 2017

Revised: August 10, 2017

Accepted: August 11, 2017

\section{Corresponding Author}

Andrey Bychkov, MD, PhD

Department of Pathology, Faculty of Medicine,

Chulalongkorn University, Rama IV Rd., Pathumwan,

Bangkok 10330, Thailand

Tel: +66-2-256-4235

Fax: $+66-2-652-4208$

E-mail: andrey.b@chula.ac.th
Thyroid carcinoma is one of the leading malignancies in Thailand increasingly prevalent in the female population. Fine-needle aspiration (FNA) cytology is a widely used diagnostic tool for evaluation of thyroid nodules and thyroid cancer. Thyroid FNA is a routine procedure universally performed in Thai hospitals by a variety of clinical specialists. Manual guidance is the first-line choice complemented by ultrasound assistance in selected cases. Despite national guidelines recommendations, the diagnostic criteria and terminology of the Bethesda System for Reporting Thyroid Cytopathology (TBSRTC) was slowly adopted in the local settings. Currently, the Bethesda system is actively promoted by the local professional societies as a uniform reporting system. Experience with thyroid FNA has been rarely reported to date-only a handful of publications are available in local journals. Our review, in addition to presenting various aspects of thyroid FNA in Thailand, established for the first time national references for a certain statistical outputs of TBSRTC based on the original multi-institutional cohort. The risk of malignancy in 2,017 operated thyroid nodules collected from three tertiary thyroid cancer centers was $21.7 \%, 14.7 \%, 35.9 \%, 44.4 \%, 76.7 \%$, and $92.6 \%$ for categories I to VI, respectively. The malignancy risk in several diagnostic categories (II to IV) was higher than the risk estimated by TBSRTC and recent meta-analysis studies. We endorse the use of uniform terminology of the Bethesda system in Thailand, which will help facilitate communication among diverse medical professionals involved in the management of patients with thyroid nodules, to share local experience with the international audience.

Key Words: Fine-needle aspiration cytology; Thyroid fine-needle aspiration; The Bethesda System for Reporting Thyroid Cytopathology (TBSRTC); Review; Thailand
Fine-needle aspiration (FNA) entered the clinical practice around 1930s, which was highlighted by the landmark paper by Martin and Ellis. ${ }^{1}$ Further elaboration of FNA by the Swedish school in the mid-century was crucial for the establishment of the technique and its worldwide acceptance. ${ }^{2}$ Thyroid, owing to its easy access, was one of the first organs to be practiced. ${ }^{3}$ Since that time, the technique has gained popularity and is now commonly used as a standard method for initial diagnosis of lesions in various anatomic sites/organs.

Thyroid nodules are common, with a prevalence ranging $20 \%-$ $60 \%$ depending on the screening approach, age, sex, iodine status, and other factors. ${ }^{4}$ Thyroid cancer is the most serious clinical condition behind thyroid nodule. Thyroid cancer is one of the most common malignancies in Thai women; its prevalence is ranked fourth and its incidence is ranked seventh. ${ }^{5}$ Recent reports found that papillary carcinoma incidence increased and follicular carcinoma incidence decreased in Thailand due to higher recognition of microcarcinomas, iodination policy, and changes in histological classification. ${ }^{6,7}$ Thyroid FNA is the most widely used diagnostic test for the management of thyroid nodules.

Thyroid cytology is considered as an effective screening and diagnostic tool for rendering a management decision. Thyroid FNA significantly reduces unnecessary surgery, which, in turn, can prevent associated complications and save excessive costs. ${ }^{8}$ The procedure can be performed by different practitioners including endocrinologists, surgeons, otolaryngologists, radiologists, and pathologists. Thyroid FNA can be guided manually or with the help of ultrasound imaging. ${ }^{8}$ Aspiration of thyroid nodules is safe and rarely causes serious outcomes. ${ }^{9}$ The complications may include local infection, hematoma, and vasovagal reflex. ${ }^{10}$

This article represents an overview of the thyroid FNA practice in Thailand. Information was provided by cytopathologists from 10 different institutions around the country via direct interviews and supplemented by available publications from the Thai series and original data. 


\section{HISTORY OF THYROID FINE-NEEDLE ASPIRATION PRACTICE IN THAILAND}

It is unclear in exactly what year thyroid FNA practice has started in Thailand. It is known that endocrinologists were the pioneers to experience thyroid FNA in Thailand. Aside from performing the procedure, they were also responsible for interpretation of the cytologic findings. Pathologists started to play a role in this area as interpreters of thyroid cytology after 1986. Initially, it was started by senior pathologists from the Institute of Pathology, a referral pathology laboratory center, and Ramathibodi Hospital, a large university based hospital. At present, almost all cases of thyroid FNA cytology are signed out by certified pathologists. General cytopathology and thyroid cytology are the essential parts of the training program for anatomic pathology residents. In addition, there are few endocrinologists signing out thyroid FNA in academic centers. Currently, there is no specific law forbidding medical doctors from practicing pathology or cytology in Thailand; hence, officially it is not illegal for clinicians to sign out pathology cases. Cytotechnologists are not involved in thyroid FNA since their major role is confined to performing cervical screening on Pap smears.

\section{FINE-NEEDLE ASPIRATION PERFORMERS}

FNA procedure is universally performed by clinicians, including endocrinologists, surgeons, radiologists, otolaryngologists, and general practitioners. In academic environment, inexperienced trainees (i.e., residents, young fellows) are frequently responsible to perform FNA, which may contribute to relatively high rates of non-diagnostic results (see below). There are very few pathologists performing this procedure where rapid onsite evaluation can be carried out. The eminent benefit is that, in case of unsatisfactory results, repeat aspiration can be done while the patients are waiting in the aspiration venue, and that preliminary diagnosis may sometimes be provided. Attending clinicians will be able to commence appropriate therapeutic approaches. Thus, patients are more satisfied with the procedure and the waiting time is cut short. However, the disadvantage is that it is time consuming for the pathologists who have to perform the procedure. In general, there is no financial incentive for those who perform FNA in public hospitals. To our knowledge, such services are available only in university based centers by a few dedicated cytopathologists. Core needle biopsy of thyroid nodules is an alternative diagnostic approach performed by some clinicians; however, this practice is very uncommon in Thailand.

\section{PREPARATION OF THYROID CYTOLOGY SAMPLES}

The technique of a smear preparation is rather standard. Briefly, after a smear is placed on a glass slide, another slide is laid on top of the sample material, and then each slide is pulled apart to spread the sample into a thin layer. Both slides are submitted for further staining. Wet smears are fixed in $95 \%$ ethyl alcohol or with spray fixatives while air-dried smears are left unfixed. The staining methods for thyroid cytology are not much different between each institute. Conventional Papanicolaou stain is used for wet smears, and air dried samples are stained with Diff-Quik method. Liquid-based preparation for thyroid FNA cytology is rarely used in Thailand, because most cytopathologists are not familiar with the technique and are not trained to interpret these cytologic smears. To our knowledge, this method is used only in a few institutions, which are basically private hospitals.

\section{THYROID CYTOLOGY REPORTING SYSTEM}

Currently, there is no standard format used by all cytopathologists across Thailand, but the Bethesda System for Reporting Thyroid Cytopathology (TBSRTC) is supposed to be the most widely accepted method for reporting thyroid cytopathology. In addition, the Bethesda system is acclaimed by most clinicians and has recently been incorporated into the residency and fellowship training programs in the relevant clinical fields, including otolaryngology, endocrinology, and general surgery. It is also credited in the national guidelines for the diagnosis and treatment of thyroid cancer released by the National Cancer Institute of Thailand. ${ }^{11}$

The Bethesda system has started to be widely recognized locally since 2010 after the well-illustrated explanatory notes were published. ${ }^{12}$ Prior to the era of TBSRTC, the cytologic reports of thyroid nodules in Thailand were not standardized and varied significantly among institutions and pathologists. At that time, cytology reporting of thyroid lesions was based on specific diagnosis of the lesions, e.g., hyperplasia, thyroiditis, equivocal, goiter, etc. Nowadays, the Bethesda terminology is consistently employed for indeterminate nodules from the categories III, IV, and V. At the same time, benign and malignant lesions are often signed out with a specific diagnosis. Another different issue is that, contrary to TBSRTC recommendations, aspirates with cystic fluid only were considered as benign by some readers and were signed out accordingly. Otherwise, the Bethesda criteria of adequacy that require six groups of 10 well-visualized follicular cells are widely accepted. ${ }^{13}$ 


\section{QUALITY ASSURANCE}

External quality assurance program for Thai pathologists is aimed to standardize their competencies in cytology interpretation. The program is set up and supported by the Thai Society of Cytology (http://www.thaicytology.org/). All enrolled participants are granted certificates upon successful completion. The cases, which are distributed to all participants, consist of cytology cases from different organs/systems including the thyroid gland. So far, there has been no nationwide thyroid FNA cytologic-histological correlation program similar to the recent Korean multi-institutional project. ${ }^{14}$ This issue, as a measure of the quality control, is partially resolved in our original series described below.

\section{ANCILLARY TESTS}

Ancillary methods for thyroid FNA, e.g., immunocytochemistry and molecular studies, are not routinely used in Thailand. Immunostaining in thyroid pathology, either surgical or cytopathology, is not much used because of its insufficient accuracy in distinguishing benign from malignant follicular-patterned lesions and other limitations. ${ }^{15,16}$ Immunocytochemistry on cell blocks is infrequently employed for differential diagnosis of certain malignancies, such as papillary carcinoma (thyroid transcription factor 1 [TTF-1], thyroglobulin), medullary carcinoma (TTF-1, calcitonin, carcinoembryonic antigen), and metastatic adenocarcinoma (cytokeratin $7, \mathrm{CDX} 2)^{17}$

Molecular techniques for preoperative evaluation of indeterminate thyroid nodules are currently being increasingly adopted in the United States. ${ }^{18}$ Mutation testing is one of the approaches, which potentially can be implemented in our local settings. For example, a presence of the $B R A F^{\mathrm{V} 600 \mathrm{E}}$ mutation is highly concordant with malignant thyroid nodules. ${ }^{18}$ However, several limitations including high cost, limited access to equipment, uncertain regulations, and lack of local studies interfere with potential implementation of the molecular testing in Thailand. ${ }^{19}$

\section{SUMMARY ON FINE-NEEDLE ASPIRATION STUDIES AND UTILITY OF THE BETHESDA SYSTEM IN THAILAND}

Three major national academic centers from geographically different parts of the country (King Chulalongkorn Memorial Hospital, Bangkok; Srinagarind Hospital, Khon Kaen; Maharaj Nakorn Hospital, Chiang Mai), where the leading authors are affiliated, were queried to provide their data on thyroid FNA over the applicable time period, 5-6 years. Since the terminology of TBSRTC was not uniformly used in local settings, especially in the early 2010s, we converted all the cytological diagnoses to the Bethesda system categories. ${ }^{13,20}$ Category I (non-diagnostic), in addition to initially unsatisfactory smears, included samples signed out as hemorrhagic content, old hemorrhagic content, cyst with hemorrhage, cystic fluid, and no cells. Category II (benign) included FNA diagnosed as nodular goiter, multinodular goiter, adenomatous goiter/nodule, Hashimoto's/lymphocytic thyroiditis, and colloid fluid/cyst. Categories III-V were usually signed out according to the Bethesda terminology. Category VI (malignant) referred to various malignancies according to their histological type, e.g. papillary carcinoma, anaplastic carcinoma, lymphoma, etc. All the patients who underwent thyroid FNA were matched with thyroid surgical pathology database to find their histological follow-up. Surgical pathology reports were analyzed with a special emphasis on malignancy.

In addition, PubMed and Google Scholar were searched for a combination of keywords: "Thailand," "thyroid," "FNA," and "cytology". All available publications in English and Thai languages released since 1990 were reviewed to obtain information on cytological diagnosis and cytological-histological correlations. The same adjustment of cytological diagnosis to the Bethesda terminology as described above was done, where possible. We found 11 publications (including eight in Thai language) from nine institutions published in local journals from 1991 to $2017 .^{20-30}$ Currently, there are no published Thai data on thyroid FNA in international journals.

There are several statistical outputs of the Bethesda system. The most acknowledged is a risk of malignancy (ROM), and additional are distribution of fine-needle aspiration cytology samples by the Bethesda category and operation/resection rate, i.e. ratio of surgically excised nodules to all nodules sampled by FNA within a category. Estimated ranges of ROM for the diagnostic categories were provided in the original Bethesda publication. ${ }^{13}$ These ranges were further adjusted to the so-called actual ROMs as per numerous original studies and meta-analysis (Table 1). ${ }^{31-33}$ Statistical outputs of the Bethesda system serve as a quality control tool for individual institution and demonstrate concordance with or deviation from national and international standards.

Distribution of thyroid FNA diagnoses by the Bethesda system has been rarely addressed in the Thai publications. ${ }^{20}$ Our own data based on 7,447 samples from two institutions are presented in Table 2. There was a high variability not only between the hospitals, but also between departments of the same hospital where the smears were signed out. A notable finding was a high 
Table 1. Implied and actual ROM according to the Bethesda diagnostic categories

\begin{tabular}{|c|c|c|c|c|c|c|c|}
\hline \multirow{2}{*}{ Source } & \multirow{2}{*}{ Parameter } & \multicolumn{6}{|c|}{ Mean \% (95\% Cl) } \\
\hline & & 1 & $\|$ & III & IV & V & $\mathrm{VI}$ \\
\hline Cibas et al. (2009)13 & Estimated ROM & $1-4$ & $0-3$ & $5-15$ & $15-30$ & $60-75$ & $97-99$ \\
\hline Bongiovanni et al. $(2012)^{31}$ & Actual ROM, meta-analysis $(n=6,362)$ & 16.8 & 3.7 & 15.9 & 26.1 & 75.2 & 98.6 \\
\hline Sheffield et al. (2014) ${ }^{32}$ & Actual ROM, meta-analysis $(n=8,044)$ & $18.7(11-26)$ & $6.5(5-9)$ & $28.3(19-38)$ & $33.1(27-40)$ & $65(50-79)$ & $98.6(98-100)$ \\
\hline Krauss et al. $(2016)^{33}$ & Actual ROM, meta-analysis $(n=8,214)$ & $12(9-14)$ & $5(3-7)$ & $17(11-23)$ & $25(20-29)$ & $72(61-84)$ & $98(97-99)$ \\
\hline
\end{tabular}

$\mathrm{ROM}$, risk of malignancy; $\mathrm{Cl}$, confidence interval.

Table 2. Distribution of thyroid FNA diagnoses by the Bethesda system

\begin{tabular}{|c|c|c|c|c|c|c|c|c|}
\hline \multirow{2}{*}{ Hospital } & \multirow{2}{*}{ Period years } & \multirow{2}{*}{$\begin{array}{l}\text { Thyroid } \\
\text { nodules }\end{array}$} & \multicolumn{6}{|c|}{ No. (\%) } \\
\hline & & & I & $\|$ & IIII & IV & V & $\mathrm{VI}$ \\
\hline$\overline{\mathrm{KCMH} \text { (Department of Pathology), Bangkok }{ }^{20}}$ & $2010-2015$ & 2,762 & $1,314(47.6)$ & $1,127(40.8)$ & $108(3.9)$ & $72(2.6)$ & $53(1.9)$ & $88(3.2)$ \\
\hline KCMH (Department of Endocrinology), Bangkok & 2015-2017 & 1,542 & $196(12.7)$ & $1,274(82.6)$ & $4(0.3)$ & $37(2.4)$ & $23(1.5)$ & $8(0.5)$ \\
\hline Chiang Mai University & $2011-2015$ & 3,143 & $672(21.4)$ & $2,141(68.1)$ & $47(1.5)$ & $87(2.8)$ & $43(1.4)$ & $153(4.9)$ \\
\hline
\end{tabular}

FNA, fine-needle aspiration; KCMH, King Chulalongkorn Memorial Hospital.

Table 3. Malignancy rates of the adjusted Bethesda categories by cytological-histological correlation

\begin{tabular}{|c|c|c|c|c|c|c|c|c|}
\hline \multirow{2}{*}{ Hospital } & \multirow{2}{*}{ Study cohort } & \multirow{2}{*}{ Operated nodules } & \multicolumn{6}{|c|}{ Risk of malignancy in the Bethesda category (\%) } \\
\hline & & & I & $\|$ & III & IV & V & $\mathrm{VI}$ \\
\hline Srinagarind Hospital, Khon Kaen²1 & $1984-1990$ & 101 & $\mathrm{n} / \mathrm{a}$ & 11.4 & $\mathrm{n} / \mathrm{a}$ & 12.5 & $\mathrm{n} / \mathrm{a}$ & 100 \\
\hline Ramathibodi Hospital, Bangkok ${ }^{22}$ & 1988-1990 & 77 & $\mathrm{n} / \mathrm{a}$ & 8.6 & 31.3 & $\mathrm{n} / \mathrm{a}$ & $\mathrm{n} / \mathrm{a}$ & 75 \\
\hline Chiang Mai University ${ }^{23}$ & 1996-1999 & 230 & $\mathrm{n} / \mathrm{a}$ & 2.5 & $\mathrm{n} / \mathrm{a}$ & 22.6 & $\mathrm{n} / \mathrm{a}$ & 90.2 \\
\hline Chiang Mai University ${ }^{24}$ & $1992-2000$ & 174 & $\mathrm{n} / \mathrm{a}$ & 5.1 & $\mathrm{n} / \mathrm{a}$ & 30.6 & 50 & 88.2 \\
\hline Chonburi Hospital25 & 1999-2003 & 97 & 17.4 & 9.1 & $\mathrm{n} / \mathrm{a}$ & 15.4 & 33.3 & 100 \\
\hline Songklanagarind Hospital, Hat Yai² & 1999-2003 & 341 & $\mathrm{n} / \mathrm{a}$ & 8.5 & $\mathrm{n} / \mathrm{a}$ & 23.2 & 68 & 73.9 \\
\hline Ratchaburi Hospital27 & 2001-2005 & 101 & $\mathrm{n} / \mathrm{a}$ & 11.4 & $\mathrm{n} / \mathrm{a}$ & $\mathrm{n} / \mathrm{a}$ & 71.4 & 100 \\
\hline Buddhachinaraj Phitsanulok Hospital28 & 2005-2009 & 234 & 14.3 & 6.8 & 57.1 & 6.1 & 92.9 & 100 \\
\hline Ramathibodi Hospital, Bangkok ${ }^{29}$ & 2005-2008 & 469 & 28.4 & 9.5 & $\mathrm{n} / \mathrm{a}$ & 42.4 & 86.7 & 100 \\
\hline Siriraj Hospital, Bangkok ${ }^{30}$ & 2002-2004 & 60 & $\mathrm{n} / \mathrm{a}$ & 5.6 & $\mathrm{n} / \mathrm{a}$ & 37.5 & $\mathrm{n} / \mathrm{a}$ & 100 \\
\hline
\end{tabular}

Modified from Limlunjakorn et al. J Med Assoc Thai 2017;100:783-92, with permission of Medical Association of Thailand..$^{20}$

n/a, not available.

rate of non-diagnostic category, which approached almost 50\% at the King Chulalongkorn Memorial Hospital (KCMH), Bangkok. This extremely high rate was addressed in our previous study. ${ }^{20}$ Briefly, it was attributed to several factors such as unskilled operators (resident physician trainees), absence of ultrasound guidance, and high prevalence of cystic nodules in the local population. ${ }^{20}$ Currently, a special training program for residents is implemented to fix this issue. It is interesting that another department at the same hospital (Department of Endocrinology), where the sampling is performed by experienced staff and often with ultrasound guiding and rapid onsite evaluation, had much more acceptable level of non-diagnostic aspirates, $12.7 \%$ (Table 2). Cyst fluid only is another contributing factor to the non-diagnostic category. ${ }^{13,34}$ Based on our experience at the KCMH, 10\% (Department of Pathology) to 40\% (Department of Endocrinology) of all non-diagnostic smears were cyst fluid only aspirates.

Benign thyroid FNA samples were the most prevalent among all the diagnostic categories (Table 2), which is concordant with the international experience. ${ }^{31-33}$ Collectively, indeterminate categories III-V were $4.2 \%$ to $8.4 \%$ (Table 2). Resection rates for each diagnostic category based on 5,905 FNA from the $\mathrm{KCMH}$, Bangkok and Chiang Mai University were as follows: $13.3 \%$ (category I), 22.0\% (category II), 30.3\% (category III), 68.6\% (category IV), 56.3\% (category V), and 50.2\% (category VI).

Local experience with thyroid FNA in the pre-Bethesda era is summarized in Table 3. There were only 10 publications in 23 years, which basically had obvious limitations including small sample size, poor design, poor data presentation, etc. There was a high diversity in the terminology used. None of the recent studies published in 2010-2013 adopted the Bethesda system. After adjustment according to TBSRTC criteria, we found that ROM in each category was generally comparable to the range described by the Bethesda system (Table 3). The issue of indeterminate nodules was not well explored, partially due to diverse terminology. To 
Table 4. Risk of malignancy per the Bethesda diagnostic category

\begin{tabular}{|c|c|c|c|c|c|c|c|c|}
\hline \multirow{2}{*}{ Hospital } & \multirow{2}{*}{ Year } & \multirow{2}{*}{$\begin{array}{c}\text { Operated } \\
\text { nodules }\end{array}$} & \multicolumn{6}{|c|}{ Risk of malignancy in the Bethesda category, $n(\%)$} \\
\hline & & & 1 & $\|$ & III & IV & V & $\mathrm{Vl}$ \\
\hline $\mathrm{KCMH}$, Bangkok ${ }^{20}$ & 2010-2015 & 457 & 20/104 (19.2) & 29/207 (14) & $11 / 29(37.9)$ & 9/43 (20.9) & $22 / 27(81.5)$ & $44 / 47(93.6)$ \\
\hline Srinagarind Hospital, Khon Kaen & 2011-2015 & 701 & $60 / 265(22.6)$ & $37 / 243(15.2)$ & 23/70 (32.9) & $14 / 24(58.3)$ & $25 / 32(78.1)$ & $62 / 67(92.5)$ \\
\hline Chiang Mai University & 2011-2015 & 859 & $35 / 161(21.7)$ & $76 / 513(14.8)$ & $8 / 18(44.4)$ & $36 / 66(54.5)$ & 19/27 (70.4) & $68 / 74(91.9)$ \\
\hline Mean/Total & & 2,017 & $115 / 530(21.7)$ & $142 / 963(14.7)$ & $42 / 117(35.9)$ & $59 / 133(44.4)$ & $66 / 86(76.7)$ & 174/188 (92.6) \\
\hline
\end{tabular}

conclude, a majority of existing publications do not adequately represent the Thai experience with thyroid FNA.

To address cytologic-histologic correlations and the ROM for the Bethesda diagnostic categories, we collected a cohort of 2,017 thyroid nodules with surgical follow-up from three institutions (Table 4). Malignant diagnoses on histopathology were mainly papillary carcinoma, followed by follicular and Hurthle cell carcinomas, as well as rare cases of anaplastic, insular, and medullary thyroid carcinomas, thyroid lymphomas and secondary malignancies. Mean ROM for all the categories except for malignant in our cohort was higher than the ROM estimated by TBSRTC or provided by the meta-analysis studies (Table 1). We found particularly high malignancy rate for the categories II (14.7\%), III (35.9\%), and IV (44.4\%) whereas a ROM in malignant category (92.6\%) was lower than expected. There may be several reasons which contribute to these deviations, such as interpretation errors, co-existence of dominant benign nodule and cancer, tertiary center bias, etc. In addition, there was a variation among the three institutions. For instance, the low ROM for category IV and high ROM for category $\mathrm{V}$ was noted in the KMCH (Table 4). Nevertheless, we believe that our multi-institutional study has established for the first time a reference range of the ROM for the Bethesda diagnostic categories in Thailand.

\section{CONCLUSION}

Thyroid FNA is a routine procedure universally performed in Thai hospitals by a variety of clinical specialists. The number of thyroid aspirations is growing, which is reflected by the increasing workload of general and head-neck pathologists and also cytopathologists who basically evaluate cytologic smears. TBSRTC was slowly adopted in local settings, but currently it is actively promoted as a uniform reporting system by the local professional societies. This review, in addition to presenting various aspects of thyroid FNA in Thailand, provides for the first time national references for several statistical outputs of the Bethesda system based on our original multi-institutional cohort. A notable finding was that the ROM in several diagnostic categories (II to
IV) was higher than the malignancy risk established by TBSRTC. We endorse the use of uniform terminology of the Bethesda system in local settings, which will help facilitate communication among diverse medical professionals involved in the management of patients with thyroid nodules, and with the international audience.

\section{Conflicts of Interest}

No potential conflict of interest relevant to this article was reported.

\section{Acknowledgments}

We wish to acknowledge the contribution of Dr. Panudda Srichomkwun, MD (Division of Endocrinology and Metabolism, Department of Medicine, Faculty of Medicine, Chulalongkorn University).

\section{REFERENCES}

1. Martin HE, Ellis EB. Biopsy by needle puncture and aspiration. Ann Surg 1930; 92: 169-81.

2. Diamantis A, Magiorkinis E, Koutselini H. Fine-needle aspiration (FNA) biopsy: historical aspects. Folia Histochem Cytobiol 2009; 47: 191-7.

3. Bibbo M. Comprehensive cytopathology. Philadelphia: Saunders, 1991.

4. Dean DS, Gharib H. Epidemiology of thyroid nodules. Best Pract Res Clin Endocrinol Metab 2008; 22: 901-11.

5. Tangjaturonrasme N, Vatanasapt P, Bychkov A. Epidemiology of head and neck cancer in Thailand. Asia Pac J Clin Oncol 2017 Aug 16 [Epub]. https://doi.org/10.1111/ajco.12757.

6. Bychkov A. A pathologist's perspective on thyroid cancer trends in Thailand. Cancer Epidemiol 2017; 47: 133-4.

7. Bychkov A, Hirokawa M, Jung CK, et al. Low rate of noninvasive follicular thyroid neoplasm with papillary-like nuclear features in Asian practice. Thyroid 2017; 27: 983-4.

8. Pisharodi L, Guiter G, Layfield L. Fine-needle aspiration biopsy. In: 
Gnepp DR, ed. Diagnostic surgical pathology of the head and neck. 2nd ed. Philadelphia: Saunders Elsevier, 2001; 1069-130.

9. Sanchez MA, Stahl RE. The thyroid, parathyroid, and neck masses other than lymph nodes. In: Koss LG, Melamed MR, eds. Koss' diagnostic cytology and its histopathologic bases. 5th ed. Philadelphia: Lippincott Williams \& Wilkins, 2006; 1148-85.

10. Busseniers AE, Silver SA. Fine-needle aspiration cytology of the thyroid. In: Oertli D, Udelsman R, eds. Surgery of the thyroid and parathyroid glands. Berlin Heidelberg: Springer-Verlag, 2007; 61-80.

11. Chindavijak S, Panchan V, Chaiwerawattana A, Imsamran W. Guidelines for the diagnosis and treatment of thyroid cancer. Bangkok: Kosit Press Co., Ltd., 2015; 114.

12. Ali SZ, Cibas E. The Bethesda System for Reporting Thyroid Cytopathology: definitions, criteria, and explanatory notes. New York: Springer, 2010.

13. Cibas ES, Ali SZ; NCI Thyroid FNA State of the Science Conference. The Bethesda System For Reporting Thyroid Cytopathology. Am J Clin Pathol 2009; 132: 658-65.

14. Kim M, Park HJ, Min HS, et al. The use of the Bethesda System for Reporting Thyroid Cytopathology in Korea: a nationwide multicenter survey by the Korean Society of Endocrine Pathologists. J Pathol Transl Med 2017; 51: 410-7.

15. Bychkov A, Sampatanukul P, Shuangshoti S, Keelawat S. TROP-2 immunohistochemistry: a highly accurate method in the differential diagnosis of papillary thyroid carcinoma. Pathology 2016; 48: 425-33.

16. Rosai J, Kuhn E, Carcangiu ML. Pitfalls in thyroid tumour pathology. Histopathology 2006; 49: 107-20.

17. Rottuntikarn W, Wangsiricharoen S, Rangdaeng S. Cytomorphology and immunocytochemistry of columnar cell variant of papillary thyroid carcinoma. Cytopathology 2017; 28: 338-41.

18. Nikiforov YE. Role of molecular markers in thyroid nodule management: then and now. Endocr Pract 2017; 23: 979-88.

19. Bychkov A. Prevalence of BRAFV600E mutation in Asian patients with thyroid cancer. Malays J Pathol 2017; 39: 95-6.

20. Limlunjakorn P, Keelawat S, Bychkov A. Evaluation of thyroid fine needle aspiration cytology by the Bethesda reporting system: a retrospective analysis of rates and outcomes from the King Chulalongkorn Memorial Hospital. J Med Assoc Thai 2017; 100: 783-92.

21. Himakoun L, Kanjanavirojkul N, Vatanasapt V, Jaroensiri DJ, Aranyasen O. Fine needle aspiration cytologic diagnosis of the thyroid nodule in Srinagarind Hospital. Srinagarind Hosp Med J 1991; 6: 243-51.
22. Issarapan P, Kulapaditharom B, Chiemchanya S. Diagnostic value of fine needle aspiration cytology in thyroid nodule: experience in the ENT department, Ramathibodi Hospital. Thai J Otolaryngol Head Neck Surg 1991; 6: 133-9.

23. Settakorn J, Chaiwun B, Thamprasert K, Wisedmongkol W, Rangdaeng S. Fine needle aspiration of the thyroid gland. J Med Assoc Thai 2001; 84: 1401-6.

24. Pattarasakulchai T, Sittitrai P, Mahanupab P. Fine needle aspiration biopsy (FNAB) in management of thyroid nodules. Chiang Mai Med Bull 2002; 41: 51-7.

25. Pradittaphonlert V. Fine needle aspiration biopsy (FNAB) of thyroid nodule at Chonburi Hospital. Chonburi Hosp J 2004; 29: 75-82.

26. Sinkijcharoenchai W, Pruegsanusak K, Jantharapattana K. Management of thyroid nodules in Department of Otolaryngology. Songklanagarind Med J 2005; 23: 303-11.

27. Nopkunwijai A. Fine needle aspiration cytology (FNAC) of thyroid nodule in Ratchaburi Hospital. Region 6-7 Med J 2006; 25: $211-7$.

28. Eamchan P. Diagnosis of thyroid nodules by fine needle aspiration biopsy in Buddhachinaraj Phitsanulok Hospital. Buddhachinaraj Med J 2010; 27: 170-6.

29. Himakhun W, Chansom R, Aroonroch R, Pongtippan A. Fine needle aspiration of thyroid: a cyto-histopathological correlation in Ramathibodi Hospital. J Med Assoc Thai 2012; 95 Suppl 1: S74-8.

30. Boonyaarunnate T, Amornpichetkul K. Advantage of frozen section in management of thyroid nodule with preoperative fine needle aspiration in Siriraj Hospital, Bangkok, Thailand. Asian Arch Pathol 2013; 9: 57-63.

31. Bongiovanni M, Spitale A, Faquin WC, Mazzucchelli L, Baloch ZW. The Bethesda System for Reporting Thyroid Cytopathology: a meta-analysis. Acta Cytol 2012; 56: 333-9.

32. Sheffield BS, Masoudi H, Walker B, Wiseman SM. Preoperative diagnosis of thyroid nodules using the Bethesda System for Reporting Thyroid Cytopathology: a comprehensive review and meta-analysis. Expert Rev Endocrinol Metab 2014; 9: 97-110.

33. Krauss EA, Mahon M, Fede JM, Zhang L. Application of the Bethesda classification for thyroid fine-needle aspiration: institutional experience and meta-analysis. Arch Pathol Lab Med 2016; 140: 1121-31.

34. Takada N, Hirokawa M, Suzuki A, Higuchi M, Kuma S, Miyauchi A. Reappraisal of "cyst fluid only" on thyroid fine-needle aspiration cytology. Endocr J 2017; 64: 759-65. 